Meta

Journal des traducteurs

Translators' Journal

\title{
The Mentions of Equivalence in Translation
}

\section{Alan K. Melby}

Volume 35, numéro 1, mars 1990

Actes du colloque international " La traduction proligère "

URI : https://id.erudit.org/iderudit/003618ar

DOI : https://doi.org/10.7202/003618ar

Aller au sommaire du numéro

Éditeur(s)

Les Presses de l'Université de Montréal

ISSN

0026-0452 (imprimé)

1492-1421 (numérique)

Découvrir la revue

Citer cet article

Melby, A. K. (1990). The Mentions of Equivalence in Translation. Meta, 35(1),

207-213. https://doi.org/10.7202/003618ar d'utilisation que vous pouvez consulter en ligne.

https://apropos.erudit.org/fr/usagers/politique-dutilisation/ 


\title{
THE MENTIONS OF EQUIVALENCE IN TRANSLATION
}

\author{
ALAN MELBY \\ Brigham Young University, Provo, USA
}

The purpose of this paper is to lift an unnecessary burden from the shoulders of many translators. That burden is the assumption that all meaning in connection with the translation of texts is something which is independent of any particular human language and culture. Once this burden is removed, translation can be viewed not as the transfer of meaning but as the search for functional equivalences in particular situations. The mentions of equivalence in translation can then increase, without fear of theoretical impropriety.

First we will examine a few definitions of translation and discuss their reliance on a particular view of mainstream linguistic theory. Second, we will peek at the philosophical roots of mainstream linguistics and consider an alternative linguistic theory. And finally, we will propose an alternative view of translation based on specifications of equivalence.

\section{DEFINITIONS OF TRANSLATION AND VIEWS ON MEANING}

Roger Bell (1987), in an article published in META, defines translation as a process whereby the translator decodes a message from a text in the source language and reencodes the message into the target language. This same general definition of translation can be found in many articles and books on translation theory. For example, Mildred Larson (1984: 3) says "translation consists of transferring the meaning of the source language into the receptor language." And Danica Seleskovitch (1976: 95) explains that translators and interpreters both "communicate the meaning of the original message."

Everyone seems to agree on the importance of meaning or message in translation. The question raised by this paper is not the importance of meaning, but whether meaning is independent of any particular human language.

Bell (1987: 413) suggests that concepts are indeed independent of any particular language and asks that we view a concept such as TREE as a polyhedron with a side for each language known by a polyglot. Larson (1984: 37) suggests that in translation, the form changes but the meaning is "held constant", and her diagram of translation shows only one item labelled meaning with an arrow from the source text and an arrow to the target text. The writings of Bell and Larson both suggest that they view meaning as something independent of source and target languages (and their associated cultures). Seleskovitch (1976: 110) argues that meaning is in a "nonverbal, shapeless state" and seems to imply that meaning is neutral and can be rendered in one language or another, although her position is not as clear.

Many, if not most translation theorists, including Bell and Larson, view meaning as language-independent. However, the view that meaning is language-DEPENDENT is perhaps more viable. In this alternative view, each language has its own meaning system, and one can find correspondences between systems. These correspondences can be generalizations, such as entries in a bilingual dictionary (which result in poor translations when applied without regard to context), or equivalences that only apply to a particular text and a particular translation in a particular situation. 
There ARE translation theories based on this alternative view. One example is the text-based Leipzig School (Neubert 1985).

There is a constant tension between the language-independent and the languagedependent views of meaning. Take, for example, the fact that people do seem to communicate fairly well using translations. Any translator who does not believe this should promptly stop translating. Many people use this fact as evidence that meaning is languageindependent, because otherwise translation would be impossible. However, it is also a fact that translation is very difficult and uncertain. Any translator who does not believe this should ask for a reduced fee on the next translation job. One could just as well use this fact as evidence that meaning is language-dependent, because otherwise translation would be much easier.

It is difficult to discuss the independent-dependent issue because it is so fundamental that it is usually not even identified as an issue. Let us look at two very restricted examples in hopes of better discussing the difference between the two sides of the issue.

First, consider an extremely simple translation between meters and yards. One can convert the length of an object from metric to British units without going through any neutral intermediate unit of measurement. This corresponds to the position that meaning is language-dependent, but translation is still possible. The metric and British systems share the notion of length and dividing length into units, but length is not divided into any universal units that exist independent of meter and yard. Meters and yards are each motivated units (based on human anatomy and the circumference of the earth, respectively), but neither could be predicted by an alien as the unit that would be used by earthlings. So length is universal but any particular unit of length is not.

Next, consider a simple translation between video display and printed display of a text using a microcomputer. Ignoring most of the complexities of font and format, a text may have a neutral intermediate form consisting of ASCII codes. The same ASCII code can be sent to a video display unit, producing a character in an 8 by 14 cell of pixels, or to a laser printer, producing a different-size character at 300 dots per inch. The ASCII code might be viewed as the media-independent meaning of the character. So ASCII codes can be viewed as a universal meaning behind a character, independent of any particular output device. Note that ASCII is still arbitrary. Although it has been adopted as an international standard (ISO 646) it would not necessarily have been developed in a parallel world. There is nothing universal about it.

Now, to return to the central question concerning human languages, is actual translation more like converting between two separate systems or like going through a neutral third system? The answer, of course, is yes. This response is not just whimsical. Technical terminology in a particular domain can be based on a neutral system that is independent of the human languages being used. But a text containing general vocabulary often participates in a meaning which is specific to a particular language, culture, and situation.

This paper thus suggests that some aspects of meaning are language-independent and some are language-dependent. This is not really a problem once it is recognized. It does, however, create problems to attempt to force all meaning into one slot or the other. Treating technical terminology like general vocabulary denies international standards, but treating general vocabulary like technical terminology suffocates true creativity.

Translators may not be to blame for the confusion over the nature of meaning. They are in part victims of a deep confusion within theoretical linguistics. Although translation theory is not necessarily based solely on linguistic theory, linguistic theory should at least be relevant. American Structuralism claimed that each language must be analyzed in its own terms, while Generative Grammar claims that one simply sets the values of some parameters of Universal Grammar, and, like magic, one has the grammar of a particular 
language (Sells 1985: 26, 197). Also, Generative Grammar claims that semantics is interpretive, that is, entirely derived from syntactic structure. However, with all its claims to universality, Generative Grammar is mute on the question of translation, not even suggesting how to semantically relate the lexical items of two languages. Bell has perhaps misunderstood de Saussure when he suggests that the signified element is universal across languages. But is it any better to say nothing at all about such an important topic? The typical translation theorist is too polite to criticize linguistic theory and instead puts together a translation theory on some other basis.

The author of this paper is an instructor of general linguistic theory by profession (and secondarily an accredited translator), so he permits himself to be openly critical of mainstream linguistics.

\section{PHILOSOPHICAL ROOTS AND AN ALTERNATIVE LINGUISTIC THEORY}

It is natural to ask on what basis mainstream linguistics claims that there are universals underlying all natural languages. The main basis is a claim from some branches of philosophy that the world DIVIDES ITSELF into classical categories. A classical category is a mathematical set, all members of which are on an equal basis and whose membership criterion is well-defined. The LAYERS of syntax and semantics in mainstream linguistics imply that meaning is built up compositionally, from the bottom (i.e., primitive categories), following the syntactic relations that tie words together. Words are assumed to be linked to combinations of universal, primitive language-independent categories. The semantic layer defines for each sentence one or several meanings which are supposedly independent of ALL context (including situation and intent). Then, entering the layer of pragmatics, context is used to eliminate some of these computed meanings or extend them. The first two layers supposedly come up with all possible "literal" meanings, which are based on the way the world really is, independent of context (Newmeyer 1986: 66).

Of course, despite what they are taught, every translator knows that this is false, since meaning is very sensitive to context, even so-called literal meaning. Consider an example from Terry Winograd, the question Is there any water in the refrigerator? In the context of a normal American family, it would be a question about whether there is a pitcher in the family refrigerator containing enough cold water (above zero degree Celsius, yet cold, probably below 10 degrees) to pour into a glass and have a good drink. However, a scientist asking another scientist this same question may be asking whether there is any substance in the laboratory refrigerator containing any $\mathrm{H}_{2} \mathrm{O}$ that might interfere with an experiment using microwaves. Which is the literal meaning? Is it truly independent of context? If one tries to list all the possible meanings in all conceivable contexts, this is an admission that meaning is indeed dependent on context. If one argues that the literal meaning is the one that is most likely in a normal context, then this is also an admission that meaning is dependent on context. There really is no meaning that is independent of all context.

However, the folklore of the literal meaning of a sentence persists, especially in linguistic theory. Perhaps this is because we are not aware of using context when we understand language and because we restrict our examples to normal sentences which can be treated like technical terminology, in that technical terminology is independent of further context once the domain has been specified. We specify a pseudo-technical domain called normal, which limits the interpretation of each word to a short list of precisely defined word senses. Any apparent counter-example (a sentence that requires a special context or has a special interpretation) is dismissed by a linguist as being strange, when it is exactly the strange examples that show the importance of context. In gambling, this would be 
called stacking the deck and would be strongly frowned on. In linguistics, it is called an idealization necessary to make the study of language feasible. It unfortunately makes the sentences studied by linguistics very boring. Mainstream linguistics, with its assumption of context-independent syntax and semantics, applies only to controlled texts which can be viewed as consisting of technical terminology in the normal domain, not to truly natural language.

There are several ways to deal with the fact that the predictions of mainstream linguistics are wrong. One way is to ignore linguistic theory. Another is to continually find ways to deal with the exceptions, the cases where context IS important. Another way, a rather radical way, is to challenge the philosophical foundations of mainstream linguistics.

An important foundation, the assumption that the world divides itself up into classical categories, is being challenged by a group of linguists, including the well-known George Lakoff. This assumption is also being challenged by philosophers in the tradition of Wittgenstein and Heiddeger. It is even being challenged in the domain of artificial intelligence by distinguished researchers such as Terry Winograd. The alternative proposed by these linguists, philosophers, and AI researchers is to assume that each system of language and culture divides up the world in its own way. This implies that there will be discrepancies between the meaning systems of various languages.

Of course, closely related languages with similar cultures will demonstrate smaller discrepancies between their meaning systems. And technical terminology is a system which is the result of a technical society or culture which can span several languages. Technical terminology IS based on classical categories, but these categories are still artificial. The world does not necessarily divide itself up according to any particular technical terminology; people divide it up in various ways at particular stages of technical development.

Turning to general vocabulary, one might argue that every language would have a word for a dog, so $d o g$ is a classical category independent of any language. However, general vocabulary is not based on classical categories. One piece of evidence is that all members of a classical category are on an equal basis, yet some members of general vocabulary categories are better members than others. For example, there is a fuzzy boundary between $d o g$ and wolf, and some very small or very large dogs are not considered as typical as, say, a spaniel. Another piece of evidence is that classical categories are either primitive or are built up from primitive categories, yet most commonly shared general vocabulary categories are at the genus level, with less agreement at more specific and more general levels. Classical categories would be precisely the same at the most specific, primitive level.

Although it is not often understood, even by Generative grammarians, the assumption that a sentence has an absolute literal meaning independent of all context and independent of any culture implies that the world does divide itself up into absolute, language-independent categories, which are the same from the perspective of any culture in any world. The alternative assumption being presented here is that categories of general vocabulary are cultural, even when they appear to be universal. Shared categories are the result of shared culture, based on shared experiences interpreted in similar ways. These shared experiences are primarily based on the fact that humans have a shared set of physical senses and live on the same planet. As an illustration and to assist in thinking about this problem, consider the following. We might have considerably less common experience with a intelligent being who lives in the center of a cloud of gas and who lacks experience with color, objects, and gravity as we know them. Would such a being divide up the world the same way we do? How different would we find the language of such a being; would we even call it language? 
One assumption is that the world divides itself up into the same categories whether we have gas bodies or solid bodies. The alternative assumption is that the world exists but does not divide itself up into categories; beings or machines that deal with categories create their own. Neither assumption denies that we do indeed live on planet Earth. Neither approach confirms or denies the existence of God. In one view, seeing things the way God does would consist of using the same absolute categories that God has understood; in the other view, God's way of seeing things comes from within God. In summary, the standard assumption is that the world divides itself up into categories; the altemative assumption is that world is divided into categories in various ways. It is likely impossible to prove which assumption is correct, so the rest of this paper will arbitrarily take the alternative approach.

A linguistic theory based on this alternative assumption is not layered the way mainstream linguistics is. Instead, sentences are only considered in context. And several dimensions of analysis, including grammatical, lexical, rhetorical, logical, and stylistic are studied in parallel, with each dimension being somewhat independent of the others, rather than layered. An example of such an alternative approach to linguistics is that of J.-M. Zemb of the Collège de France.

\section{AN ALTERNATIVE APPROACH TO TRANSLATION}

The alternative approach to linguistics just described is based on the assumption that each language categorizes the world in its own way. This suggests an alternative approach to translation. Instead of describing translation as the process of going into a language-independent meaning and then back out into another language, one can view translation as the process of writing a text in the target language, keeping it equivalent to the source text in various ways. (The Leipzig School calls this text constrained writing.) Such an approach is actually used by many translators, but when they explain it in terms of translation theory, they usually feel obliged to somehow reconcile equivalence with the more standard model of translation as the transfer of language-independent meaning. One example is an excellent article by Roda Roberts and Maurice Pergnier in META (1987: 392-402) which deals with equivalence in a revealing way but then tries to reconcile equivalence with a meaning transfer model.

How DOES this equivalence approach to translation deal with meaning? It assumes that the source text and the target text are each meaningful in context to a speaker of the appropriate language. It also assumes that there is a set of specifications which indicate which types of equivalence are to be emphasized for this particular text, with relative priorities to help resolve conflicts. These specifications are naturally based on the purpose of the translation.

Typical specifications might concern register, time, dialect, naturalness, place, culture, format, logical content, and structure. These are all aspects of translation that have been discussed for many years. But instead of looking for THE one correct translation of a text (presumably the one which has the same language-independent meaning), the translator simply produces one translation (among a variety of equally acceptable ones) which is consistent with the given specifications.

Granted, this view of translation does not explain exactly how a translator makes the mental leap across the chasm between the source situation and the target situation. But this could be a strength rather than a weakness, since it is unlikely that any one method or process is used by all translators. In literal translation, sometimes the source structure is pulled over to the target language and adjusted as needed. This method generally produces somewhat ugly results. Another possible method is to pull over the logical framework and fill it in with equivalent objects and actions. An interesting consequence 
of the language-dependent view of meaning is that any progress in understanding monolingual writing as an expression of an objective in a situation (on which mainstream linguistics is mute) will probably apply directly to translation as a form of constrained writing.

Returning to the constraints in the specifications of equivalence, many translators will recognize in the following discussion that they actually work in terms of equivalence rather than neutral meaning. For example, a translation will normally have the same register as the source text, but the specifications for translating a maintenance manual may indicate a change to a simpler register, depending on the audience. Neutral, languageindependent meaning transfer would imply that the register would always be the same in the source text and the target text. An approach using specifications of equivalence has flexibility built into it.

Normally, a translation will be made to appear as if it were written in the same time frame as the source text, but the specifications for a translation of a 15th century French play may indicate either 15th century English or 20th century English, depending on the hoped-for impact on the audience. Which century expresses the real meaning of the text? Here again, an equivalence approach is more flexible than a meaning transfer approach.

Typically, a translation should sound like it was written in the target language in the target country, but when the source text contains items specific to the source language culture not found in the target language culture, the writer of the specifications must choose between naturalness and culture. A specification of naturalness may require a Polynesian reference to a mango to be replaced with a Canadian reference to an apple. A specification of source-culture orientation may retain the mango but make it impossible for the translation to sound like it was written in Canada in English. How does neutral meaning help the translator discuss these options? Not at all.

Specifications of format will determine whether to keep a poem as a rhyming poem and with what rhyming structure. But again, there is probably no universal rhyme. Yet it can be important in a given situation to specify what kind of rhyme will be used.

Most translations will be specified to have equivalent logical content as the source text, that is, to have equivalent objects doing equivalent things to equivalent objects. Logical content is often equated with meaning, but this leads only to fruitless discussions of what else should be included in meaning (such as the aspects of language we have already discussed, namely, time, place, register, culture, and format). It is perhaps better to treat logical content as one type of equivalence and specify, for each translation, what kind of equivalence is required.

Of course, in a text whose primary purpose is to provide information, the logical content should be equivalent on an item-by-item basis. For example, a report of items found at the scene of a crime should keep a red shoe as a red shoe. However, in a play, a red shoe might become a blue shoe in the translation if it fulfills the specifications. In translation of advertising materials, the specifications may allow dramatic departure from equivalence of logical form, so long as a certain rhetorical objective is maintained in a way that fits the target culture.

So what does all this change in the way translators actually do their work? Fortunately, very little. If it did, then this paper would be suggesting that most translators are doing bad work. There is no such suggestion. Instead, it suggests a change in the way translators view what they are already doing. It claims that mainstream linguistics and mainstream translation theory may be wrong, or at least influenced by misguided views of language. Meaning is not based on absolute, classical categories independent of perception. Categories are more classical for technical terminology and more based on metaphor, metonymy, and analogy for general vocabulary. So translators are not looking for 
the one absolutely correct translation of a text, they are trying to produce a well-written text which conforms to the given specifications.

This paper apologizes for the author's inability to convince mainstream linguistics to consider the proposed alternative. Nevertheless, it is hoped that it has given some relief of the burden on translators of dealing with meaning as an absolute something floating somewhere between the source and the target text.

\section{REFERENCES}

BELL, Roger T. (1987): “Translation Theory: Where Are We Going?", META, 32-4, December.

LAKOFF, George (1987): Women, Fire, and Dangerous Things: What Categories Reveal about the Mind, University of Chicago Press.

LARSON, Mildred L. (1984): Meaning-based Translation: A Guide to Cross-language Equivalence, University Press of America.

NEUBERT, Albrecht (1985): Text and Translation, Leipzig.

NEWMEYER, Frederick J. (1986): Linguistic Theory in America, Academic Press.

ROBERTS, Roda and Maurice PERGNIER (1987): «L'Équivalence en traduction», META, 32-4, December.

SELLS, Peter (1985): Lectures on Contemporary Syntactic Theories, Center for the Study of Language and Information, Stanford.

SELESKOVITCH, Danica (1976): "Interpretation, A Psychological Approach to Translation", in Translation, Richard Brislin (ed.), Halsted, a division of John Wiley \& Sons.

WINOGRAD, Terry and Fernando FLORES (1987): Understanding Computers and Cognition, AddisonWesley. 